\title{
Motion Effects of the Ship on Crew Performance
}

\author{
Hongtae Kim ${ }^{1}$, Wook Hyun Ha ${ }^{2}$, Jun-Hyuk Jang ${ }^{1}$, Tae Hyun Fang ${ }^{1}$, Seungbin $\mathrm{Oh}^{1}$ \\ ${ }^{1}$ Korea Institute of Ocean Science and Technology, Daejeon, 305-343 \\ ${ }^{2}$ Instrumentation \& Control Engineering Deaprtment, KEPCO E\&C, Gyeonggi-do, 446-713
}

\begin{abstract}
Objective: The aim of this study is to provide a current knowledge of the multiple issues regarding motion effects on crew performance. Background: The motions of the ship may create motion sickness, nausea and vomit. Also, these motions also disturb the balance of crew members, increase the energy expenditure of crew for shipboard work, and result in increased levels of injury and fatigue. However, the motion effects of the ship on crew performance has not been thoroughly investigated. Method: Participants $(\mathrm{N}=10)$ were engaged in an experiment in 2 experimental environments(training ship and ship handling simulator) and 2 navigational conditions(day and night). The COP(Center of Pressure) data were recorded as an objective measure of postural balance control and the SSQ(Simulator Sickness Questionnaire) was used as a subjective measure of sickness. Results: The results showed that COP has a no significant difference based on experimental environments, but significant effect on SSQ. Conclusion: During the virtual simulator navigation, subjects showed significant SSQ level changes, which included decreased SSQ data. But, there is no significant difference of COP between training ship and ship handling simulator. Application: The results of this study could be applied to the next generation of ship design to decrease effect of motion at sea and to increase performance of ship crew.
\end{abstract}

Keywords: Ship motion, Motion sickness, Simulator sickness, Center of pressure, Simulator sickness questionnaire

\section{Introduction}

해양운송분야에서 선박운항자의 인적 오류에 의한 선박사 고로 피해가 막대하지만, 선박운항이자 관점에서의 안전성 평가를 위한 구체적인 수단이나 기술의 개발은 미흡한 실정 이다. 특히, 해상교통 안전성 평가를 위한 선박운항 시뮬레 이터의 실제 운항에서 발생될 수 있는 상황에 대한 현실성 과 신뢰성을 높이기 위한 정량적 지표의 개발이 시급히 요 구되고 있지만 실제 선박과 선박운항 시뮬레이터에 대한 현 실감을 높이기 위한 연구는 미약하다.

선박운항에서 해상 상태가 악화되면 선체의 동요가 커짐으 로 인해 선박운항자는 인지능력 감소, 뱃멀미(seasickness),
활동성 저하 그리고 피로 등 좋지 않은 영향을 받게 된다 (Jung et al., 2008).

평형감각 및 자세 균형은 일상생활의 모든 동작 수행에 중 요한 영향을 주는 신체를 평형 상태로 유지시키는 능력이며 감각정보 통합, 신경계 처리, 생체 역학적 요인을 포함하는 복잡한 운동 조절 작업이다(Cohen et al., 1993; Schlmann et al., 1987).

뱃멀미 증상은 선박운항자의 물리적, 심리적 측면에서 작 업수행 능력이 급격히 떨어지고 정신적 활동의 지연이나 오 류를 유발하며, 회복에 상당한 시간이 소요된다.

한편, 사이버멀미에 대한 측정과 평가는, 최근 가상현실 시스템 평가의 중요 항목으로 대두되고 있는 현실감에 비해 서는 상대적으로 많은 평가 방법들이 존재한다. 뇌파, 심전

Corresponding Author: Hongtae Kim. Maritime Safety Research Division, Korea Institute of Ocean Science and Technology, Daejeon, $305-343$. Phone: +82-42-866-3643, E-mail: hongtae.kim@kiost.ac Copyright@2013 by Ergonomics Society of Korea(pISSN:1229-1684 eISSN:2093-8462). All right reserved.

(c) This is an open-access article distributed under the terms of the Creative Commons Attribution Non-Commercial License(http://creativecommons.org/licenses/by-nc/3.0/), which permits unrestricted non-commercial use, distribution, and reproduction in any medium, provided the original work is properly cited. http://www.esk.or.kr 
도, 안전도, 위전도 등의 생리신호 변화는 멀미 현상과 매우 밀접한 관계가 있는 것으로 알려져 있다(Kim et al., 2002).

생리신호 측정 외의 방법으로는 설문지 방법이 있는데 Kennedy et al.(1993)의 SSQ(Simulator Sickness Questionnaire) 설문이 가장 널리 사용되고 있으며, 이 외 에 사이버멀미의 직접적 지표는 아니나 관련 있는 지표로 신체동요를 측정하여 평가할 수도 있다.

가상현실이 주는 신체동요가 사이버멀미를 쉽게 유발한다 는 연구 결과와 함께 가상현실과 신체동요의 관계를 밝히는 많은 연구들이 진행 중에 있다(Owen et al., 1998).

해양사고의 예방을 위한 선박운항 시뮬레이터는 인간공학 적 시험평가 기법 연구가 미흡하여, 선박운항자의 운항능력 및 작업부하에 대한 정량적 분석기법의 본격적인 개발 및 활 용을 위한 인간공학적 평가기법이 부재한 실정이며, 해양사 고를 예방하기 위한 해양관련 종사자 관점에서의 관련 연구 와 예방대책이 필요할 것으로 보인다.

본 논문에서는 선박운동과 멀미의 특성, 선체동요가 선박 에 탑승한 해상승무원의 업무 수행도에 미치는 영향에 대한 관련 연구들을 리뷰하고, 업무 수행도를 저하시키는 주요 증 상인 선체동요에 따른 멀미와 선박 시뮬레이터에서의 사이 버멀미에 대한 실험 결과를 소개하였다.

\section{Ship Motion and Crew Performance}

\subsection{Ship motion}

선상환경과 육상환경의 가장 큰 물리적 측면에서의 차이 점은 해상에서 움직이는 운송기구에 탑승한다는 것이다. 전 진하는 선박이 파도를 만나면 여러 형태의 운동을 하게 되 는데, 이러한 운동 특성들에 의해 때로는 승무원과 승객들은 불쾌감을 느끼거나 각종 기기에도 나쁜 영향을 준다(Lee, 2001; SNAK, 1996).

선체의 운동을 크게 직선운동과 회전운동으로 나눌 수 있 다. 직선운동에는 전후동요, 좌우동요, 상하동요가 있으며, 회전운동에는 횡동요, 종동요, 선수동요가 있다. Figure 1은 선체운동을 보여준다.

특히, 횡동요(rolling)는 승무원과 승객에게 불쾌감을 일으 키며, 반복되는 운동으로 화물과 선박 내 각종 의장품에 손상 을 주고, 선박의 전복의 원인이 되기도 하다(SNAK, 1996).

횡동요가 작은 선박의 개발과 함께 횡동요를 감소시키는 장치의 개발하려는 노력은 오래 전부터 이루어져 왔으며, 횡 동요를 감소시키기 위한 장치에는 빌지킬(bilge keel), 감요 수조(anti-rolling tank), 핀안정기(fin stabilizer) 등이 있다. 이러한 선체동요를 감소시키기 위해 선박은 규정 이상의

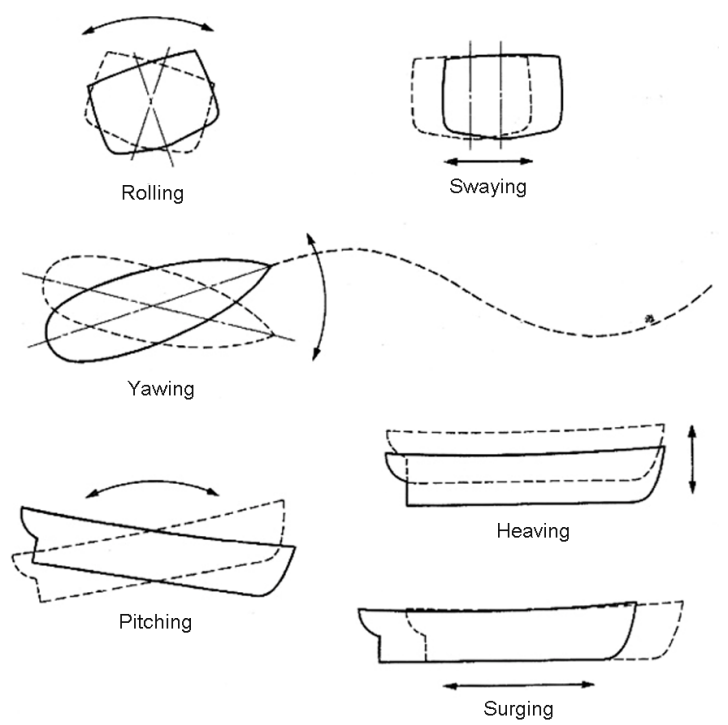

Figure 1. Ship's motions(SNAK, 1996)

조종성능을 보유하도록 국제해사기구에서 선박의 설계와 건 조를 강제 규정화하고 있으며, 선박의 조종성능과 관련한 규 정에는 침로안정성, 선회성능 그리고 정지성능이 있다.

자동차나 기차의 경우에는 대략 $1 \sim 40 \mathrm{~Hz}$ 까지의 주파수영 역과 광역 스펙트럼의 진동 특성이 인간에 미치는 영향을 고려하며, 선박의 경우는 선체의 운동이 외력인 파랑의 특성 을 따르므로, $1.0 \mathrm{~Hz}$ 미만에서의 주파수영역과 좁은 대역의 스펙트럼 특성을 갖는 운동 특성을 갖는다(Gong, 2004).

Figure 2와 같이 선박운동에 의해 유도되는 자세응답 (motion-induced interruption, MII), 신경계-호르몬계 영 향(neuro-humoral effects), 멀미(motion sickness), 안락 성 감소(discomfort) 등이 복합적으로 작용하여 선체운동에 기인한 피로(motion-induced fatigue, MIF) 유발하게 된다.

\subsection{Motion sickness}

멀미는 motion sickness, seasickness, kinetosis, travel sickness 등으로 다양하고 불리우며, 불규칙한 움직임에 대 한 신체반응으로, 시각적으로 받아들인 움직임과 전장기관의 움직임 감지 사이의 불일치가 존재할 때 일어난다.

즉, 선박, 항공기, 자동차 등 운송수단에서의 피동적인 움 직임은 내이, 눈, 관절과 인대를 통해 신호로 뇌에 전달되는 데, 서로 다른 신호들이 어울리지 않고 상반될 때 멀미가 나 타날 수 있다. 예를 들면, 배를 타고 파도를 바라보고 있으면 눈은 파도의 움직임을, 내이는 배의 움직임을 신호로 뇌에 보내게 되는데, 이 신호가 상반될 때 멀미가 일어난다.

선박 분야의 뱃멀미와 관련해서는 1970년대부터 다양 


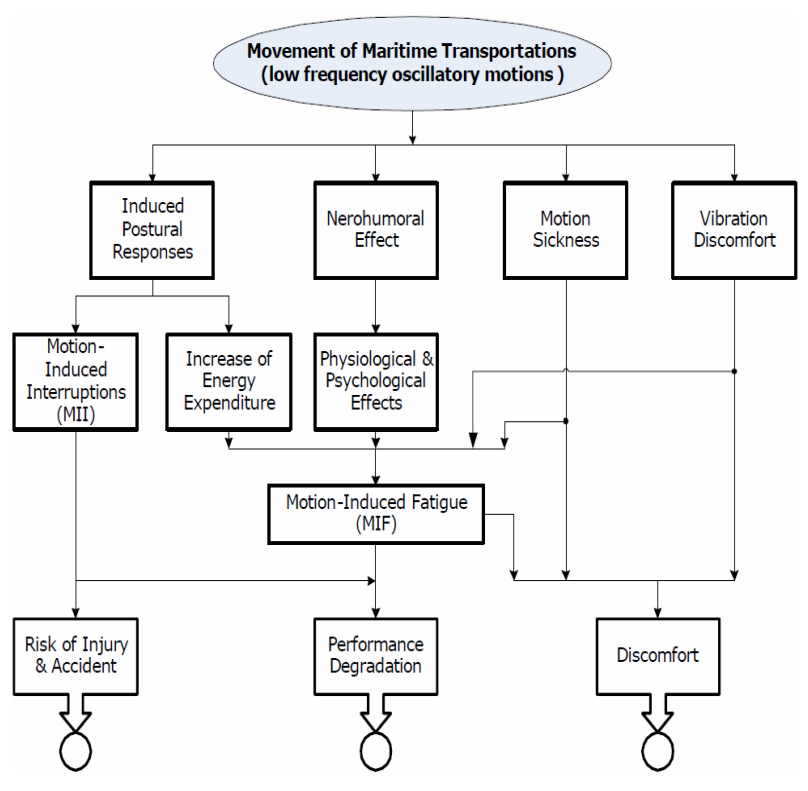

Figure 2. Effects of ship motion on crew and passenger (Gong, 2004)

한 연구사례가 보고되고 있으며, Griffin(1991b)과 Dobie (2000)의 연구에서 다양한 사례가 언급되고 있다.

영국의 Navy Medical Information Management Center 에서 1980년에서 1992년 사이에 입대한 신병 중 489,266 명이 멀미 증세를 겪었으며, 해군의 10 30\%가 일반 상태 에서 뱃멀미를 호소하는 것으로 나타났다. 또한 67 73\%의 해군 장병이 근무기간 중에 뱃멀미를 경험했으며, 42 56\% 가 지난 12 개월 중에 뱃멀미를 경험했고, 좋지 않은 해상 상 태에서는 5일간에 38 47\%의 장병이 한번 이상의 멀미 증 상을 경험한 것으로 나타났다(Stevens and Parsons, 2002).

McCauley et al.(1976)는 2시간 동안 motion에 노출되 었을 때의 구토비율인 MSI(motion sickness incidence) 를 이용하여 종동요, 횡동요, 상하동요에 따른 멀미 현상을 연구하였다. 이 연구에서 MSI가 "pitch-only" 조건에서는 9\%, "roll-only" 조건에서는 0\%로 종동요와 횡동요가 멀 미에 영향을 거의 미치지 않는다고 보고하였다. 또한 "pitch plus heave" 조건에서는 34\%, "roll plus heave" 조건에서 는 $31 \%$ 로 종동요와 횡동요는 상하동요와 조합이 되었을 때 높아짐을 알 수 있다. 그러나 이는 "heave-only"(31\%)와 유사한 MSI 점수가 나타났다. 따라서 상하운동의 선박 움직 임이 뱃멀미를 야기시키는 중요한 요소라고 제안하였다.

Lawther and Griffin(1986)은 영국 해협에서 카페리(car ferry) 의 움직임에 따른 뱃멀미 연구를 실시하였다. 그 결과 수직방향 모션에서 크기, 노출시간이 뱃멀미와 큰 상관관계 를 가지고 있었다. 수집된 데이터는 큰 여객선을 대상으로
하여 상대적으로 횡동요와 종동요의 움직임이 작았기 때문 으로 판단된다. 또한 승선위치가 모션을 인지하는데 있어 중 요한 요소임을 보고하였다.

Wertheim et al.(1995)은 Ship Motion Simulator (SMS)에서 1시간 동안 육체적인 작업과 함께 머리를 움 직일 수 있도록 하였는데, 그 결과 멀미가 매우 높게 나타 났다. 피실험자 21 명 중 10 명, 약 $48 \%$ 가 멀미 증상을 보 였다. Wertheim et al.(1996)의 연구에서는 Ship Motion Simulator(SMS)에서 자전거 작업과 함께 머리를 최대한 움직이지 않도록 하였다. 그 결과 $33 \%$ 가 $\mathrm{MSI}$ 증상을 보였 다. 이 두 연구의 결과는 단지 머리의 움직임의 차이인데, 이 는 상하운동으로 인해서이다.

Wertheim et al.(1998)는 멀미가 종동요와 횡동요에 의 해서가 아니라 상하운동에 의해서 유발된다는 기존의 주장 에 대해서 의문을 제기하였다. 종동요, 횡동요 및 상하운동 이 모두 작용할 때는 $45.5 \%$ 로 높은 비율로 멀미가 나타났 다. "heave-only" 조건과 "roll-only" 조건(3.7\%)에서는 멀미가 거의 나타나지 않았다. 종동요와 횡동요만 작용하였 을 때는 대부분 멀미 증상이 나타나지 않았고 30 명 중 1 명 (3.3\%)만 멀미 증상이 나타났다.

Bles et al.(1991)은 교육용 선박에서 실험을 수행하였다. 상대적으로 작은 선박에서는 뱃멀미에 미치는 영향이 높다 고 보고하였다.

\subsection{Performance effects}

Kehoe et al.(1983)은 무기체계 운용성에 선체동요가 미치는 영향을 분석한 연구에서 미 해군 함정의 전체 전투 가용도가 겨울시즌에는 $15 \%$ 정도에 못 미친다고 보고하고 있다.

무기체계의 운용성에 영향을 미치는 요인은 여러 가지가 있을 수 있으나, 승조원의 능력은 업무 수행도를 결정하는 중요한 요인이므로, 선체동요가 승무원의 능력에 미치는 영 향을 매우 크다고 할 수 있다.

Wertheim(1998)은 선체운동에 의해 영향을 받는 업무 수행도의 장애요인을 일반 영향(general effects) 과 특별 영 향(special effects)으로 구별하여 설명하고 있다.

일반 영향은 움직이는 환경에서 업무 수행도에 나타나는 영향을 나타내며 다음과 같이 세 가지로 구분될 수 있다.

- 동기적 특성 (motivational nature): 선체동요에 반응하는 심리적, 생리적 영향으로 멀미, 구토, 졸음 등의 증세로 업 무 수행을 위한 동기를 감소시킴.

- 에너지 특성 (energetical nature): 선상에서의 물리적 작 업을 수행하는데 겪는 어려움을 나타내며, 예로는 균형유 
지를 위한 근육의 추가부담으로 인한 선체운동 기인 피로 (motion-induced fatigue) 가 있음.

- 생체역학 특성 (biomechanical nature): 동요상황에서 균형유지 실패로 인해 업무 수행에 방해를 받는 것으로, 선박운동에 의해 유도되는 자세응답(motion-induced interruption)이 대표적인 예임.

특별 영향은 움직이는 환경에서 인간 수행도에 영향을 미 치는 특별한 인간의 능력이나 기능을 나타내며, 항해와 같은 복합 업무(complex task), 레이더 추적 등과 같은 인지 업무 (cognitive task), 수동 추적과 같은 운동 업무(motor task) 및 시각/청각 식별과 같은 지각 업무(perceptual task)로 구분할 수 있다.

\section{Method}

본 실험에서는 선박운항 시뮬레이터에서 운항자가 받는 현실감에 대한 정량적 평가를 위해 실제 선박의 선체운동에 의한 평형감각이상과 선박운항 시뮬레이터에서의 인공적인 시각자극을 받은 선박운항자가 사이버멀미로 인한 평형감각 기관의 이상을 비교 평가하기 위해 수행하였다.

실제 선박의 선박운동과 선박운항 시뮬레이터의 가상 항 해 영상에 대해 선박운항자의 신체 요동과 주관적인 멀미 느낌을 알아보기 위하여 다수의 선박운항자를 대상으로 같 은 해상상황에서 신체동요와 주관적인 멀미 느낌을 측정 분 석하여 선박운항 시뮬레이터의 현실감 정도를 평가하고자 하였다. 또한 실제 선박에서 선박운항자의 균형 조절능력과 주관적 멀미 느낌을 평가하여 추후 선박운항 시뮬레이터에 서의 현실감 평가를 위한 기초자료로 사용하고자 한다.

\subsection{Participants}

한국해양대학교 항해학과 4 학년 항해사 후보생 5 명과 일 반인 남자 5명으로 이루어진 피실험자 집단에 대한 실제 선 박과 선박운항 시뮬레이터에서의 신체동요 및 주관적 평가 를 실시하였다.

피실험자의 평균 나이는 24.5세이며, 실험에 참가하기 전 에 실험의 목적, 내용 및 위험성 등에 대해 설명을 들었으며, 실험참여에 대한 서면동의를 받았다.

1 차 분석 결과, 항해사 후보생과 일반인의 데이터 사이에 통계적으로 차이가 없음이 확인되어, 모든 분석은 10 명의 동일 피실험자 집단으로 가정하여 이루어졌다.

\subsection{Experimental design}

신체동요의 정도는 동요의 범위, 표준편차 등이 가장 기본 적으로 많이 활용되고 있으나, 이 외에도 동요면적, 동요거 리 등이 민감도가 좋은 지표로 알려져 있다.

실험에 사용한 독립변수는 2 수준의 실험환경과 2 수준의 운항조건으로 처리하여 총 4 개(2X2) 조합조건에서 측정이 이루어지도록 하였다.

2수준의 실험환경은 선박운항자가 신체동요를 계측하는 장소를 말하며, 서론에서 언급한 바와 같이 한국해양대학교 한바다호 선교(ship bridge)와 한국해양과학기술원 선박운 항 시뮬레이터이다. 2수준의 운항조건은 선박운항 시간대를 나타내는 것으로 낮 시간(4 5시) 과 밤 시간(9 10시)이다. 종속변수는 신체동요의 측정자료인 $\mathrm{COP}$ (Center of Pressure) 와 주관적 설문인 SSQ로 자료를 수집하였다.

\subsection{Experimental procedure and apparatus}

실제 선박에서의 신체동요 측정을 위하여 Figure 3 과 같 이 한국해양대학교의 한바다호 선교에서 선박운항자의 신체 동요를 측정하였으며, Figure 4와 같이 한국해양연구원에서 개발한 선박운항 시뮬레이터에서 선박운항자의 신체동요를 측정하였다.

한국해양대학교의 한바다호는 2005년에 건조되었으며, 전장 117.2 미터, 폭 17.8 미터, 총톤수 6,686톤으로 최대 246명이 탑승가능한 크루즈형 실습선이다.

또한 한국해양과학기술원의 선박운항 시뮬레이터는 영상 은 곡면으로 연결된 3 개의 대형 스크린에 3 대의 프로젝터에 의해 만들어졌다. 영상의 내용으로는 실제 한바다호의 선체 와 같은 운동 특성을 지니고 있으며 운항 항로와 동일하게 재연된 해상상황이 표시되었다.

실제 선박에서 선박운항자의 신체동요를 측정하기 위해

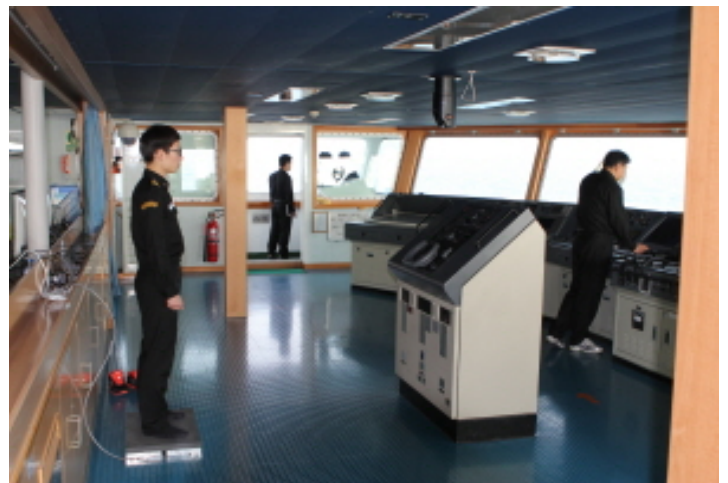

Figure 3. Training ship "Hanbada" 


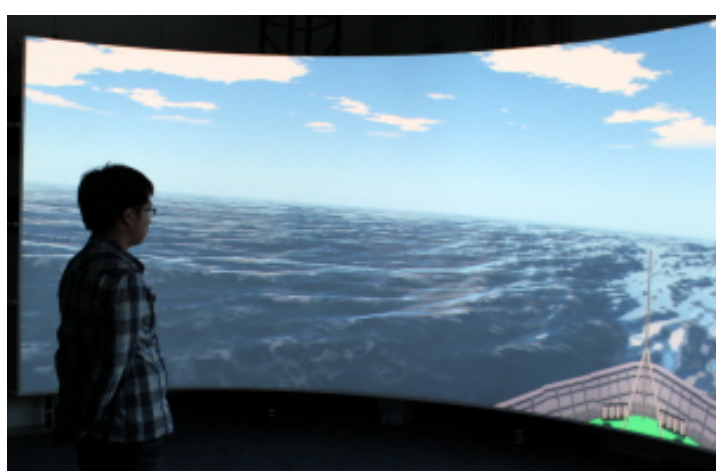

Figure 4. KIOST's ship handling simulator

선교에 설치된 $\mathrm{COP}$ 장비에 올라가 3 분 동안 신체동요를 측 정하였으며, 선박운항 시뮬레이터에서는 5 분 동안 스크린을 주시하도록 하였고 그 후에 3 분 동안 신체동요를 측정하였 다. 실험이 종료된 직후 피실험자에게 SSQ 설문지를 작성하 도록 하였다.

$\mathrm{COP}$ 는 몸의 균형 상태를 측정하고 평가하는 것으로, Bertec사의 AM6800 모델의 데이터 앰프와 힘판(force platform)을 사용하였다. 힘판은 사각형의 강판아래 네 코 너에 설치된 로드셀과 이에 부착된 스트레인게이지(strain gauge)에 의해 세 방향의 힘 $(\mathrm{x}, \mathrm{y}, \mathrm{z})$ 과 각 축에 대한 모멘 트를 측정하게 된다.

\section{Results}

실험결과 분석을 위하여 $\mathrm{COP}$ 및 멀미의 주관적 평가 를 측정한 10 명의 자료에 대하여 정규성을 가정하고 통계 분석용 소프트웨어 Statview (5.0)를 이용하여 분산분석 (ANOVA)을 실시하였으며, 통계적 유의수준은 $5 \%$ 로 설정 하였다.

\subsection{COP}

각 실험조건에서 $\mathrm{COP}$ 측정 결과 Figure 5 와 같이 나타났 다. $\mathrm{COP}$ 에 대한 분산분석을 수행한 결과, 실험환경에 대한 주 효과 $(\mathrm{F} 1,76=2.066, p=0.155)$ 와 운항조건 $(\mathrm{F} 1,76$ $=0.011, p=0.917)$ 가 유의수준 $5 \%$ 에서 유의하지 않은 것으로 나타났다. Table 1 은 $\mathrm{COP}$ 에 대한 분산분석 결과를 보여주고 있다.

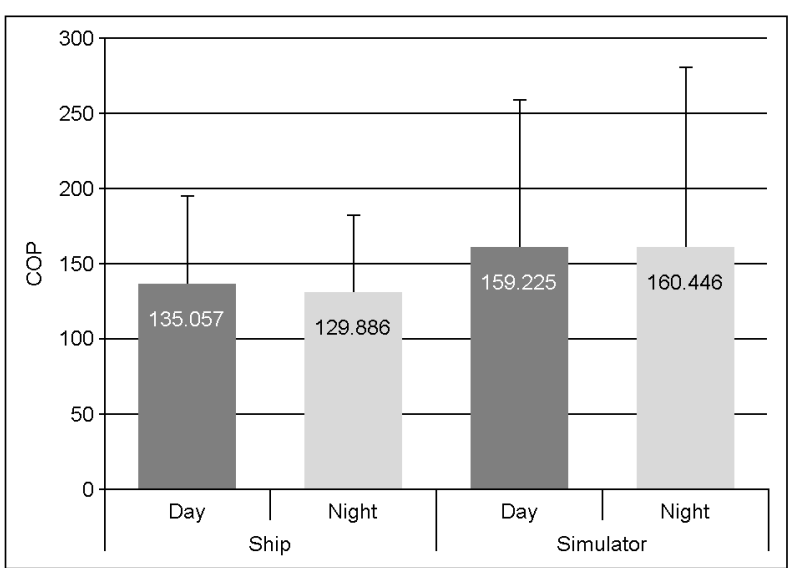

Figure 5. Change in COP based on experimental environment

Table 1. ANOVA analysis for COP

\begin{tabular}{c|c|r|r|r|r}
\hline 요인 & $\mathrm{DF}$ & \multicolumn{1}{c|}{$\mathrm{SS}$} & \multicolumn{1}{c|}{$\mathrm{MS}$} & $F$-값 & $P$-값 \\
\hline 실험환경 & 1 & 14992.113 & 14992.113 & 2.066 & .155 \\
\hline 운항조건 & 1 & 79.172 & 79.172 & .011 & .917 \\
\hline $\begin{array}{c}\text { 실험환경 X } \\
\text { 운항조건 }\end{array}$ & 1 & 202.384 & 202.384 & .028 & .868 \\
\hline 잔차 & 76 & 551471.193 & 7256.200 & & \\
\hline
\end{tabular}

\subsection{SSQ}

각 실험조건에서 $\mathrm{SSQ}$ 설문을 분석한 결과 Figure 6와 같이 나타났다. SSQ에 대한 분산분석을 수행한 결과, 실험환 경에 대한 주 효과 $(\mathrm{F} 1,16=10.752, p=0.005)$ 가 유의수 준 $5 \%$ 에서 유의한 것으로 나타났으며, 운항조건에서의 주

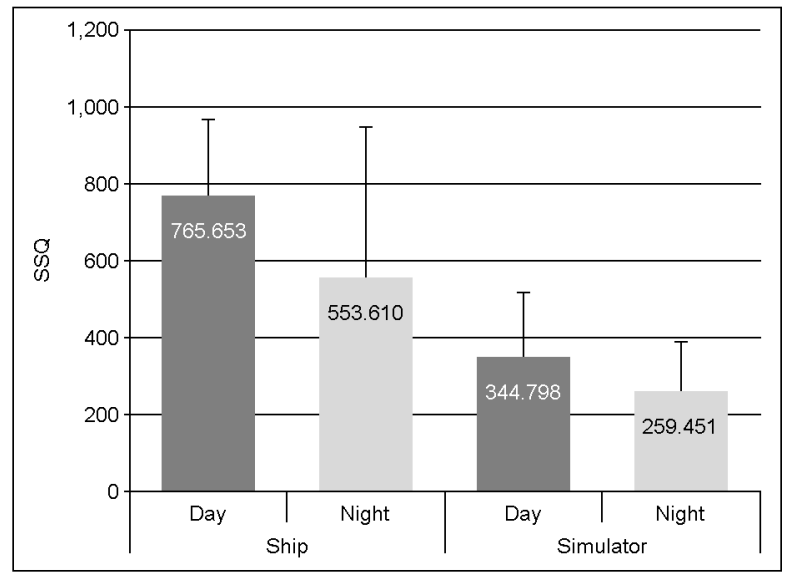

Figure 6. Change in SSQ based on experimental environment 
효과(F1, $16=1.860, p=0.192)$ 는 유의수준 $5 \%$ 에서 유 의하지 않은 것으로 나타났다. Table 2 는 SSQ에 대한 분산 분석 결과를 보여주고 있다.

Table 2. ANOVA analysis for SSQ

\begin{tabular}{c|c|c|c|r|c}
\hline 요인 & $\mathrm{DF}$ & $\mathrm{SS}$ & $\mathrm{MS}$ & $F$-값 & $P$-값 \\
\hline 실험환경 & 1 & 639054.846 & 639054.845 & 10.752 & $.005^{*}$ \\
\hline 운항조건 & 1 & 110550.896 & 110550.896 & 1.860 & .192 \\
\hline $\begin{array}{c}\text { 실험환경 } \mathrm{X} \\
\text { 운항조건 }\end{array}$ & 1 & 20064.922 & 20064.922 & .338 & .569 \\
\hline 잔차 & 16 & 950932.748 & 59433.297 & & \\
\hline \multicolumn{5}{c}{} & \multicolumn{4}{|c}{$p<0.05$}
\end{tabular}

\section{Discussion}

본 논문에서는 실제 선박과 선박운항 시뮬레이터에서의 선박운항의 현실감을 $\mathrm{COP}$ 측정 및 $\mathrm{SSQ}$ 설문을 통해 정량 적으로 평가하려고 시도하였다.

$\mathrm{COP}$ 측정 결과 실제 선박과 선박운항 시뮬레이터에서의 결과가 유의수준 $5 \%$ 에서 유의하지 않은 것으로 나타났으며, 이 결과는 선박운항 시뮬레이터가 선박운항자에게 비슷한 신체동요를 주는 것으로 판단된다. 그리고 운항조건인 낮 시 간과 밤 시간의 결과도 유의수준 $5 \%$ 에서 유의하지 않은 것 으로 나타나서 낮 시간과 밤 시간대의 신체동요가 비슷한 것으로 판단된다.

$\mathrm{SSQ}$ 분석 결과에서는 실제 선박과 선박운항 시뮬레이터 에서의 주관적 멀미 느낌의 정도가 유의수준 $5 \%$ 에서 유의 한 것으로 나타났으며, 실제 선박에서의 SSQ가 더 높은 것 으로 평가되었다. 이러한 결과는 실제 선박에 탑승한 시간이 선박운항 시뮬레이터에 탑승한 시간보다 길기 때문인 것으 로 판단된다.

실험 결과에서 보이듯이 현재 한국해양과학기술원에서 운 영중인 선박운항 시뮬레이터는 실제 선박과 비슷한 선체운 동을 운항자에게 영상으로 제시하고 있으며, 운항자는 시각 의 느낌으로 인해 신체동요가 발생하고 그에 따른 약간의 멀 미를 느끼는 것으로 판단된다.

본 연구에서는 두 가지 실험환경과 운항조건을 단순히 개 별적으로 비교 분석하였다. 향후 더 많은 조건의 실험환경과 운항조건을 혼합하여 선박운항자에게 제시하거나 6축 모션 베이스가 탑재된 선박운항 시뮬레이터에서의 연구가 필요할 것으로 판단된다.

\section{Conclusions}

선체운동을 수반한 선박에서의 업무수행 과정에서는 멀미, 구토와 같은 신체적 반응과 균형유지를 위한 운동 기인 피로 가 발생하며, 선박운동에 의해 유도되는 자세응답에 의해 다 양한 선상 재해가 발생한다.

이러한 선체운동에 의한 선원 업무능력 저하 및 선상 재해 를 예방하기 위해서 다음과 같은 다양한 방법이 시도되고 있 다(Samson and Michael, 2002).

- 약리적 처방: 항콜린제(anticholinergics), 항히스타민제 (antihistamines)

- 생체자기제어(biofeedback): 자율훈련법

- 자연 적응: 수일에서 일주일 경과 $(5 \%$ 는 미적응)

- 설계 고려: 횡동요 감쇠장치 (anti-rolling devices), 작업 장의 배치 개선

또한 Bittner \& Guignard(1985)는 선체운동에 의한 생체 공학적/신경생리학적 위해성을 최소화 할 수 있는 전반적인 예방 및 저감 방안을 Table 3 과 같이 제시하고 있다. Table 3 에서 보는 바와 같이 선체운동의 영향을 줄이기 위한 방법

Table 3. Approaches to preventing or mitigating adverse effects of ship motion on crew(Bittner \& Guignard 1985)

\begin{tabular}{|c|c|}
\hline Approaches & Methods \\
\hline $\begin{array}{l}\text { A. Ship design and } \\
\text { systems engineering }\end{array}$ & $\begin{array}{l}\text { 1. Hull design } \\
\text { 2. Ship arrangements } \\
\text { 3. Operation and maintenance of machinery } \\
\text { and equipment } \\
\text { 4. Motion attenuation devices(e.g., fins) } \\
\text { 5. Vibration isolation and damping } \\
\text { treatments } \\
\text { 6. Isolation of special stations }\end{array}$ \\
\hline $\begin{array}{l}\text { B. Human factors } \\
\text { engineering }\end{array}$ & $\begin{array}{l}\text { 1. Arrangement and design of crew space } \\
\text { 2. Location and orientation of crew stations } \\
\text { 3. Work and task design } \\
\text { 4. Display/ control design and placement } \\
\text { 5. Optimization of ship environmental } \\
\text { factors } \\
\text { 6. Individual anti-vibration devices }\end{array}$ \\
\hline $\begin{array}{l}\text { C. Enhancing natural } \\
\text { human resistance to } \\
\text { motion effects }\end{array}$ & $\begin{array}{l}\text { 1. Optimization of work/rest and } \\
\text { duty/leave cycles } \\
\text { 2. Habituation and oscillatory motion } \\
\text { training } \\
\text { 3. Specific task training in motion } \\
\text { environment } \\
\text { 4. Crew selection } \\
\text { 5. Provision of adequate sleep }\end{array}$ \\
\hline
\end{tabular}


Table 3. Approaches to preventing or mitigating adverse effects of ship motion on crew (Bittner \& Guignard 1985) (Continued)

\begin{tabular}{l|l}
\hline Approaches & \multicolumn{1}{c}{ Methods } \\
\hline $\begin{array}{l}\text { D. Modifying adverse } \\
\text { physiological reactions } \\
\text { to motion }\end{array}$ & $\begin{array}{l}\text { 1. Optimization of crew fitness and morale } \\
\text { 2. Optimization of the immediate } \\
\text { physiologic state } \\
\text { 3. Medication }\end{array}$ \\
\hline E. Operation solutions & $\begin{array}{l}\text { 1. Strategic and tactical planning to } \\
\text { minimize routing through rough motion } \\
\text { areas }\end{array}$ \\
$\begin{array}{l}\text { 2. Tactical maneuvering compromises of } \\
\text { speed, heading and stopping time at sea }\end{array}$ \\
\hline
\end{tabular}

으로는 선박 설계 개선, 시스템 공학적 접근, 인간공학적 개 선, 개인적 저항능력 향상 및 운용 개선 등 다양한 방안이 있을 수 있다.

해상에서 선박에 탑승한 승객과 선원은 일반적인 육상에 서의 경우보다 많은 피로를 호소한다. 이러한 피로는 승객의 경우에는 승선에 따른 불쾌감을 증가시켜 안락함을 감소시 키고, 선원의 경우에는 작업효율의 저하와 업무의 집중도 감 소를 유발한다. 특히, 선원의 피로는 수행 중인 업무에 대한 실수의 발생확률을 증가시켜, 결과적으로 인적 요인에 의한 해양사고를 유발함으로써, 선박의 안전을 위협하는 중요한 요소가 되기도 한다.

그러므로, 선체운동에 의한 영향의 저감을 위한 설계의 개 선 및 효율적 운용 방안을 위한 후속 연구가 필요할 것으로 사료된다.

\section{Acknowledgements}

The contents of this paper are the results of the research project of KIOST (The Development of Human Factors Experimental Evaluation Techniques for Maritime Traffic Safety Assessment) and Ministry of Oceans and Fisheries of Korea (Development of prevention and management technology for human-related marine accident).

\section{References}

Bittner, A.C. and Guignard, J.C., Human factors engineering principles for minimizing adverse ship motion effects: Theory and practice, Naval Engineers Journal, 97(4), 205-213, 1985.

Bles, W., De Graaf, B., Keuning, J.A., Ooms, J., De Vries, J. and Wientjes, C.J.E., Experiments on Motion Sickness Aboard the M.V. Zeefakkel, Report IZF-1991-A-34, TNO Human Factors Research Institute, Soesterberg, The Netherlands; 1991.

Cohen, H., Blatchly, C.A. and Gombash, I.L., A study of the clinical test of sensory interaction and balance, Phys Ther, 73, 346-354, 1993.

Dobie, T.G., "The Importance of the Human Element in Ship Design", Proceedings of the Ship Structure Symposium, Arlington VA, June 13, 2000.

Jung, C.H. and Lee, Y.S., A study on the ships performance of T.S Hanbada (II), Journal of Navigation and Port Research, 32(5), 333 $-339,2008$.

Gong, D.S., Studies for ship-motions-effects on personnel's, Journal of Ships and Ocean Engineering, 38, 111-116, 2004.

Griffin, M.J., Sea Sickness, In AGARD (Advisory Group for Aerospace Research and Development) Lecture Series 175, Motion Sickness: Significance in Aerospace Operations and Prophylaxis, 1991.

Kehoe, J.W., Brower, K.J. and Comstock, E.N., Seakeeping and combat system performance-the operator's assessment, Naval Engineer's Journal, 256-266, 1983.

Kennedy, R.S., Lane, N.E., Berbaum, K.S. and Lilienthal, M.G., Simulator sickness questionnaire: an enhanced method for quantifying simulator sickness, The Int'l J. of Aviation Psychology, 3(3), 203-220, 1993.

Kim, Y.W., Kim, E.N. and Kim, H.T., "Perspectives of Psychophysiology in Virtual Reality", Proceedings of the Summer Conference on Korean Society for Cognitive Psychology and Biology, 59-69, 2002.

Lee, J.S., Human Factors and Ergonomics, Sigma Press, 2001.

McCauley, M.E., Royal, J.W., Wylie, C.D., O'Hanlon, J.F. and Mackie, R.R., Motion Sickness Incidence: Exploratory Studies of Habituation, Pitch and Roll, and the Refinement of a Mathematical Model, Technical Report 1733-2, Human Factors Research Inc., 1976.

Owen, N., Leadbetter, A.G. and Yardley, L., Relationship between postural control and motion sickness in healthy subject, Brain Res., 47(5), 471-474, 1998.

Samson, C.S. and Michael, G.P., Effects of motion at sea on crew performance: a survey, Marine Technology, 39(1), 29-47, 2002.

SNAK, Introduction to Naval Architecture and Ocean Engineering, DongMyung Press, 1996.

Wertheim, A.H., Heus, R. and Kistemakers, J.A., Human Energy Expenditure, Task Performance and Sea Sickness during Simulated Ship Movements, Report TNO-TM 1995-C29, Soesterberg, The Netherlands, TNO Human Factors Research Institute, 1995.

Wertheim, A.H., Bos J.E. and Bles W., Contributions of roll and pitch to sea sickness. Brain Research Bulletin, 47(5), 517-524, 1998. 


\section{Author listings}

Hongtae Kim: hongtae.kim@kiost.ac

Highest degree: $\mathrm{PhD}$, Dept. of Industrial Engineering, Korea University Position title: Principal Researcher, KIOST

Areas of interest: Usability evaluation, Maritime Human Factors

Wook Hyun Ha: hawh@kepco-enc.com

Highest degree: MS, Dept. of Industrial \& Management Engineering,

Hannam University

Position title: Assistant Manager, Instrumentaion \& Control Engineering Department, KEPCO E\&C

Areas of interest: Human Factors in Power Plants Safety

Jun Hyuk Jang: jang@kiost.ac

Highest degree: Ph.D, Dept. of Industrial Engineering, Dong-A University Position title: Research Scientist, Korea Institute of Ocean Science \& Technology (KIOST)

Areas of interest: Occupational safety, Maritime Human Factors

\section{Tae Hyun Fang: thfang@ kiost.ac}

Highest degree: Ph.D, Dept. of Mechanical Engineering, Busan National University

Position title: Principal Researcher, Korea Institute of Ocean Science \& Technology (KIOST)

Areas of interest: Sensor fusion, Target tracking, Optimal control

Seungbin Oh: ohseungbin@kiost.ac

Highest degree: MS, Dept of Industrial Engineering, Hannam University Position title: Researcher, Korea Institute of Ocean Science \& Technology (KIOST)

Areas of interest: Ergonomics, Human sensibility ergonomics

Date Received : 2013-07-01

Date Revised : 2013-08-01

Date Accepted : 2013-08-01 